\title{
COMUNICAÇÃOCIENTÍFICA
}

\section{CARACTERÍSTICAS FÍSICO-QUÍMICAS E PRODUTIVAS DAS UVAS 'ISABEL' E 'BRS-RÚBEA'SOBRE DIFERENTES PORTA-ENXERTOS NA REGIÃO NORTE DO PARANÁ ${ }^{1}$}

\author{
ALESSANDRO JEFFERSON SATO ${ }^{2}$, BRUNO JUBILEU DA SILVA², CRISTIANO EZEQUIEL DOS SANTOS ${ }^{2}$, \\ ROSEINEIDE BERTOLUCCI ${ }^{3}$, ROBERTA DOS SANTOS ${ }^{3}$, MARIANACARIELO ${ }^{3}$, MARÍLIA CHEROBIN GUIRAUD ${ }^{3}$, \\ INÊS CRISTINADE BATISTAFONSECA ${ }^{4}$, SÉRGIO RUFFO ROBERTO ${ }^{4}$
}

\begin{abstract}
RESUMO-O trabalho teve como objetivo avaliar as características físico-químicas e produtivas das videiras 'Isabel' (Vitis labrusca) e 'BRS-Rúbea' (V. labrusca) enxertadas sobre os porta-enxertos IAC 766 Campinas, IAC 572 Jales e 420 A, destinadas à elaboração de suco de uva no norte do Paraná. Após a poda de frutificação, foram registrados o número médio de gemas e o de esporões por planta, e, no momento da colheita, avaliaram-se o teor de sólidos solúveis totais (SST), acidez titulável (AT), índice de maturação (SST/AT) e pH do mosto das bagas, além da massa e comprimento dos cachos, a massa e diâmetro das bagas e o número de cachos por planta e por ha. Foram também estimadas a produção (kg/planta) e a produtividade ( $/$ ha) das combinações copa/porta-enxerto. Verificou-se que os porta-enxertos exerceram influência sobre as copas apenas em relação ao número de esporões e de gemas por planta e por ha, com destaque para a 'Isabel' sobre o 'IAC 766 Campinas'. A 'Isabel' apresentou teor de SST superior em relação à 'BRS-Rúbea', no entanto,para a AT e a SST/AT, não houve diferença significativa entre as cultivares, e para o pH do mosto da 'Isabel' foi menor em relação à 'BRS-Rubea'. Para as características físicas e produtivas, a 'Isabel' apresentou maiores valores em relação à 'BRS-Rubea'. Termos para indexação: Vitis labrusca, suco de uva, sólidos solúveis totais, acidez titulável, pH.
\end{abstract}

\section{PHYSICO-CHEMICAL AND PRODUCTIVE CHARACTERISTICS OF 'ISABEL'AND 'BRS- RÚBEA’ GRAPES ON DIFFERENT ROOTSTOCKS IN NORTH OF PARANÁ REGION}

\begin{abstract}
The aim of this research was to evaluate the physical-chemical and productive characteristics of 'Isabel' (Vitis labrusca) and 'BRS-Rúbea' (V. labrusca) vines grafted on 'IAC 766 Campinas', 'IAC 572 Jales' and '420 A' rootstocks designated for the production of grape juice in the North of Paraná. After pruning, it was registered the average number of bud and spurs per tree, and at the moment of the harvest, it was evaluated the content of the total soluble solids (TSS), tritable acidity (TA), maturation rate TSS/ $\mathrm{TA}$ and $\mathrm{pH}$ of berry must, besides the mass and the length of the bunches, the mass and the diameter of the berries and the number of bunches per tree and per ha. It was also estimated the production ( $\mathrm{kg} / \mathrm{plant})$ and productivity ( $/ \mathrm{ha}$ ) of the combinations crown/ rootstock. It was verified that the rootstocks had influenced the grapevines only in relation to the number of spurs and buds per tree and ha, with prominence to 'Isabel' over 'IAC 766 Campinas'. The 'Isabel' presented higher TSS content in relation to the 'BRSRúbea' however, for the AT and SST/AT there was no significant difference between the cultivars, and the 'Isabel' must pH was lower in relation to the 'BRS-Rúbea'. Concerning the physical and productive characteristics, the 'Isabel' presented higher values when comparing to the 'BRS Rubea'.
\end{abstract}

Index Terms: Vitis labrusca, grape juice, total solid soluble, tritable acidity, $\mathrm{pH}$.

A produção de sucos de uvas no Brasil é uma atividade em amplo crescimento, sendo que a sua comercialização em 2005 foi cerca de $25 \%$ maior do que em 2004, com um total de 131 milhões de litros, entre sucos de uvas concentrado e integral. (Mello, 2006). O crescente aumento no consumo de sucos de uva está relacionado às descobertas de que este produto, assim como o vinho, possui poder antioxidante contra doenças cardiovasculares, devido à presença de substâncias chamadas de polifenóis, que previnem a oxidação do chamado mau colesterol(Instituto de Endocrinologia e Nutrição, 2005).
A uva 'Isabel' (Vitis labrusca) é atualmente a base para o suco brasileiro (Embrapa, 2006). Entretanto, o suco elaborado dessa cultivar apresenta deficiência em cor e aroma. Portanto, para agregar cor ao suco da uva 'Isabel', geralmente são realizadas misturas com outras cultivares, como, por exemplo, a 'BRS-Rúbea' (Camargo, 2005).

A produção de uvas de qualidade destinadas à elaboração de sucos está estreitamente relacionada a diversos fatores, entre os quais, a cultivar-copa e o porta-enxerto. Dessa forma, quando se deseja estabelecer a produção de uvas para processamento

'(Trabalho 147-07).Recebido em: 12-06-2007. Aceito para publicação em 10-04-2007. Apoio CNPq.

${ }^{2}$ Aluno regular do curso de pós-graduação em Agronomia da UEL - ajsato82@yahoo.com.br. Centro de Ciências Agrárias. Caixa Postal 6001. 86051-990. Londrina-PR

${ }^{3}$ Acadêmico do curso de graduação em Agronomia da Universidade Estadual de Londrina. Centro de Ciências Agrárias. Caixa Postal 6001. 86051-990. Londrina-PR

${ }^{4}$ Prof. Adjunto do curso de Agronomia da Universidade Estadual de Londrina. Centro de Ciências Agrárias. Caixa Postal 6001. 86051-990. Londrina, PR 
em regiões onde seu cultivo é pouco conhecido, é essencial analisar a influência que esses fatores exercem sobre o sistema produtivo.

Visando a esses aspectos, o objetivo deste trabalho foi avaliar as características físico-químicas e produtivas das uvas 'Isabel' e 'BRS-Rúbea' destinadas à elaboração de sucos sobre os diversos porta-enxertos e conduzidas em sistema GDC na região norte do Paraná.

O experimento foi conduzido no município de RolândiaPR, onde foi estudado o comportamento das videiras 'Isabel' (Vitis labrusca) e 'BRS-Rúbea' (V. labrusca), enxertadas sobre os porta-enxertos 'IAC 766 Campinas' (Riparia do Traviú $x$ Vitis caribaea), 'IAC 572 Jales' (Vitis caribaeax Vitis riparia $x$ Vitis rupestris 420 A) e '420 A' (Vitis berlandieri $x$ V. riparia).

O delineamento experimental adotado foi o inteiramente casualizado,com 4 repetições, arranjadas em esquema fatorial 2x3 ( 2 cultivares-copa e 3 cultivares porta-enxerto), sendo cada parcela composta por 4 plantas. .

Logo após a poda de frutificação, foi aplicado o regulador de crescimento cianamida hidrogenada, na dose de $2,5 \%$ para a quebra de dormência das gemas.Imediatamente após a poda de inverno, foram registrados o número de esporões e de gemas por planta, a fim de estabelecer a média em cada combinação copa/ porta-enxerto.

No momento da colheita, para avaliação das características químicas das uvas das diferentes combinações copa/porta-enxerto, como teor de sólidos solúveis totais (SST), acidez titulável (AT), índice de maturação (SST/AT) e pH,foram coletadas 60 bagas de cada parcela, subdivididas posteriormente em 4 subamostras.

O teor de SST do mosto das uvas foi determinado em refratômetro digital,e o resultado,expresso em ${ }^{\circ} \mathrm{Brix}$. As determinações do $\mathrm{pH}$ e da AT do suco foram realizadas em titulador potenciométrico digital com solução padronizada de $\mathrm{NaOH} 0,1 \mathrm{~N}$, adotando-se como ponto final da titulação o $\mathrm{pH}=8,2$, e o resultado,expresso em porcentagem de ácido tartárico (Instituto Adolfo Lutz, 1985).

Por ocasião da colheita, foi registrado o número médio de cachos de cada parcela. Para a determinação das características físicas da produção, foram coletados 4 cachos por parcela, onde se avaliaram a massa $(\mathrm{g})$ e o comprimento $(\mathrm{cm})$ dos cachos, e a massa $(\mathrm{g})$ e o diâmetro das bagas ( $\mathrm{mm})$.

A comparação das médias dos tratamentos de todas as variáveis estudadas foi realizada no programa de análise estatística SISVAR (Ferreira, 2000) por meio de análise de variância complementada por Tukey, a 5\%.

De acordo com os resultados obtidos, para o número de esporões e de gemas por planta e por hectare (Tabela 1), houve interação significativa entre os fatores, onde se observou influência do porta-enxerto sobre a copa das videiras. Verifica-se que o maior número de esporões e gemas, tanto por planta como por ha, foi obtido pela cultivar Isabel sobre o 'IAC 766 Campinas'. Entretanto, observou-se que,para o número de esporões por ha, não houve diferença significativa entre a 'Isabel' sobre o 'IAC 766 Campinas' e sobre o 'IAC 572. Verifica-se também que não houve influência significativa dos porta-enxertos sobre a 'BRS-
Rúbea' e tampouco entre as cultivares-copa sobre o '420 A'.

Para as características químicas das uvas, o porta-enxerto não exerceu influência sobre as copas (Tabela 2). Verifica-se que a cultivar Isabel,independentemente do porta-enxerto, apresentou teor de sólidos solúveis totais (SST) superior à cultivar BRSRúbea , e que não houve diferença significativa quanto à acidez titulável (AT) e o índice de maturação (SST/AT). Entretanto, o pH do mosto da 'Isabel' apresentou média inferior em relação à 'BRS-Rúbea'.

Entretanto, deve-se considerar que o valor de SST apresentado pela 'Isabel' neste primeiro ano de avaliação pode ser maior, pois este foi apenas seu primeiro ano de produção e ainda não apresentava todos os seus órgãos, como as raízes, os troncos e os braços completamente desenvolvidos. Para a 'BRSRúbea', o teor de SST foi satisfatório, pois se trata de uma cultivar da qual sua principal característica é agregar cor ao suco e não açúcar.

Com relação à acidez do mosto (Tabela 2), verifica-se que,independentemente do porta-enxerto, as cultivares Isabel e BRS-Rúbea apresentaram $0,4 \%$ de ácido tartárico, resultado este bastante satisfatório, pois para a elaboração de um suco de qualidade, recomenda-se utilizar uvas com AT entre 0,4 e $0,6 \%$ (Rizzon et al., 2004).

O índice de maturação (SST/AT) das uvas 'Isabel' e 'BRS-Rúbea' também não sofreu influência dos porta-enxertos (Tabela 2). Entretanto, verifica-se que os valores obtidos (40,5 e 38,0 , respectivamente) estão dentro do limite estabelecido pela legislação brasileira (entre 15 e 45). Segundo Rizzon e Link (2006), o índice de maturação representa o equilíbrio entre o gosto doce e ácido do suco de uva, ou seja, quanto mais elevado for esse valor, mais doce este suco será.

Por se tratar de uma relação entre SST e AT, verifica-se que, embora o teor de SST obtido neste primeiro ano de produção não tenha sido elevado, o índice de maturação ficou dentro da faixa ideal para a obtenção de sucos de qualidade. Este resultado concorda com Rizzon et al. (1998), que consideram o índice de maturação a característica química mais importante no momento de se selecionarem uvas para o processamento.

$\mathrm{O}$ pH do mosto das uvas também não sofreu influência do porta-enxerto, sendo a média observada para a 'BRS-Rúbea' $(3,7)$ significativamente superior à 'Isabel' $(3,5)$. Segundo Rizzon et al. (2004), para a obtenção de um suco de uva de qualidade, o $\mathrm{pH}$ do mosto ideal deve estar entre 3,1 e 3,3, o que permite considerar que, neste primeiro ano produtivo, ambas as videiras apresentam valores bem satisfatórios.

Em relação às características físicas das uvas, observase, na Tabela 3, que a média da massa e do comprimento dos cachos da 'Isabel' (125,1 g e 11,6 cm, respectivamente) foram estatisticamente superiores aos da 'BRS-Rúbea' (83,1 g e 9,3 cm, respectivamente). O mesmo ocorreu para a média da massa das bagas (2,8 g para 'Isabel' e 2,3 g para 'BRS-Rúbea'), porém,em relação ao diâmetro das mesmas, não houve diferença significativa entre as cultivares (14,8 e 14,2 mm, respectivamente).

Observa-se, na Tabela 4, o número de cachos por planta e por hectare, a produção por planta e a produtividade, e verificase que a videira 'Isabel' apresentou superioridade em todas as 
variáveis analisadas, fato este que está diretamente relacionado à diferença de vigor entre as cultivares, pois quanto mais desenvolvidas as videiras, maior a quantidade de gemas, o que poderá resultar em maior número de cachos por planta e, conseqüentemente,por ha.

A maior produção por planta e produtividade da videira 'Isabel',em relação à 'BRS-Rúbea' (9,6kg por planta e 13,5t/ha; e $5,4 \mathrm{~kg}$ por planta e $7,5 \mathrm{t} / \mathrm{ha}$, respectivamente), ocorreu provavelmente devido às características produtivas de cada cultivar (Tabela 4).
Os resultados obtidos neste trabalho, embora preliminares, indicam que as videiras 'Isabel' e 'BRSRúbea',cultivadas na região norte do Paraná, apresentam potencial produtivo para a elaboração de sucos. No entanto, os porta-enxertos exerceram influência somente para a 'Isabel' e apenas em relação ao número de esporões e gemas, sendo que o 'IAC 766 Campinas' foi superior em relação ao 'IAC 572 Jales' e ao '420 A' para essas variáveis. Além disso, verificou-se que o sistema de condução GDC é viável para a produção de uvas com boa qualidade tecnológica para processamento de suco nesta região.

TABELA 1 - Número de esporões e gemas por planta e por ha das videiras 'Isabel' e 'BRS-Rúbea' enxertadas sobre os porta-enxertos 'IAC 766 Campinas', 'IAC 572 Jales’ e ‘420 A'. Londrina-PR, 2006.

\begin{tabular}{|c|c|c|c|c|c|}
\hline & Cultivar & 'IAC 766 Campinas' & 'IAC 572 Jales' & $' 420 A^{\prime}$ & $\mathrm{CV}(\%)$ \\
\hline Número de & 'Isabel' & $56,7 \mathrm{Aa}$ & $38,5 \mathrm{Ba}$ & $35,7 \mathrm{Ba}$ & 21,8 \\
\hline esporões/planta & 'BRS-Rúbea' & $36,0 \mathrm{Ab}$ & $39,7 \mathrm{Aa}$ & $32,5 \mathrm{Aa}$ & 21,8 \\
\hline Número de & 'Isabel' & $79.450,0 \mathrm{Aa}$ & $53.900,0 \mathrm{ABa}$ & $50.050,0 \mathrm{Ba}$ & 28,1 \\
\hline esporões/ha & 'BRS-Rúbea' & $38.400,0 \mathrm{Ab}$ & $55.600,0 \mathrm{Ab}$ & $45.500,0 \mathrm{Aa}$ & 28,1 \\
\hline Número de & 'Isabel' & $111,0 \mathrm{Aa}$ & $74,7 \mathrm{Ba}$ & $71,2 \mathrm{Ba}$ & 21,3 \\
\hline gemas/planta & 'BRS-Rúbea' & $70,5 \mathrm{Ab}$ & $78,0 \mathrm{Aa}$ & $62,0 \mathrm{Aa}$ & 21,3 \\
\hline Número de & 'Isabel' & $155.400,0 \mathrm{Aa}$ & $104.650,0 \mathrm{Ba}$ & $99.750,0 \mathrm{Ba}$ & 23,9 \\
\hline gemas/ha & 'BRS-Rúbea' & $98.700,0 \mathrm{Ab}$ & $109.200,0 \mathrm{Aa}$ & $86.800,0 \mathrm{Aa}$ & 23,9 \\
\hline
\end{tabular}

*Médias seguidas de mesma letra maiúscula nas linhas e minúscula nas colunas não diferem entre si, pelo teste de Tukey $(\mathrm{p}<0,05)$.

TABELA 2 - Teor de sólidos solúveis totais - SST ( ${ }^{\circ}$ Brix), acidez titulável - AT (\% de ácido tartárico), relação SST/ AT e pH do mosto das videiras 'Isabel' e 'BRSRúbea' enxertadas sobre 3 porta-enxertos. Londrina-PR, 2006.

\begin{tabular}{lccc}
\hline Características químicas & 'Isabel' & 'BRS-Rúbea' & $\mathrm{CV}(\%)$ \\
\hline SST $\left({ }^{\circ} \text { Brix }\right)^{\mathrm{a}}$ & $16,2 \mathrm{~A}$ & $15,2 \mathrm{~B}$ & 7,4 \\
$\mathrm{AT}(\% \text { de ácido tartárico })^{\mathrm{b} /}$ & $0,4 \mathrm{~A}$ & $0,4 \mathrm{~A}$ & 16,9 \\
Relação SST/AT & $40,5 \mathrm{~A}$ & $38,0 \mathrm{~A}$ & 21,9 \\
$\mathrm{pH}$ & $3,5 \mathrm{~B}$ & $3,7 \mathrm{~A}$ & 1,8 \\
\hline
\end{tabular}

*Médias seguidas de mesma letra maiúscula nas linhas não diferem entre si,pelo teste de Tukey $(\mathrm{p}<0,05)$

a/: Sólidos solúveis totais.

b/: Acidez titulável.
TABELA 3 - Massa $(\mathrm{g})$ e comprimento $(\mathrm{cm})$ dos cachos, massa (g) e diâmetro (mm) das bagas das videiras 'Isabel' e 'BRS-Rúbea' enxertadas sobre 3 porta-enxertos. Londrina- PR, 2006.

\begin{tabular}{lccc}
\hline Características físicas dos cachos & 'Isabel' & 'BRS-Rúbea' & CV(\%) \\
\hline Massa dos cachos (g) & $125,1 \mathrm{~A}$ & $83,1 \mathrm{~B}$ & 9,2 \\
Comprimento dos cachos (cm) & $11,6 \mathrm{~A}$ & $9,3 \mathrm{~B}$ & 5,6 \\
Massa das bagas (g) & $2,8 \mathrm{~A}$ & $2,3 \mathrm{~B}$ & 6,3 \\
Diâmetro das bagas (mm) & $14,8 \mathrm{~A}$ & $14,2 \mathrm{~A}$ & 4,1
\end{tabular}

*Médias seguidas de mesma letra maiúscula nas linhas não diferem entre si,pelo teste de Tukey $(\mathrm{p}<0,05)$

TABELA 4 - Número de cachos por planta, por ha, produção por planta (kg/planta), produtividade (t/ha) das uvas 'Isabel' e 'BRSRúbea’ enxertadas sobre 3 porta-enxertos. Londrina-PR, 2006.

\begin{tabular}{lccc}
\hline Características Produtivas & 'Isabel' & 'BRS-Rúbea' & CV(\%) \\
\hline Número de cachos/planta & $76,1 \mathrm{~A}$ & $60,2 \mathrm{~B}$ & 16,0 \\
Número de cachos/ha & $106.633,0 \mathrm{~A}$ & $77.100,0 \mathrm{~B}$ & 25,4 \\
Produção/planta (kg/planta) & $9,6 \mathrm{~A}$ & $5,4 \mathrm{~B}$ & 17,1 \\
Produtividade (t/ha) ${ }^{\mathrm{a} /}$ & $13,5 \mathrm{~A}$ & $7,5 \mathrm{~B}$ & 17,1 \\
\hline
\end{tabular}

*Médias seguidas de mesma letra maiúscula nas linhas não diferem entre si,pelo teste de Tukey $(\mathrm{p}<0,05)$.

a/: Estimativa em função da produção média por planta. 


\section{REFERÊNCIAS}

CAMARGO, U.A. Espécies e cultivares. In: EMBRAPA/CNPUV. Uva para processamento e produção. Brasília: Embrapa Informação Tecnológica, 2003. p. 34-44.

Suco de uva: matéria-prima para produtos de qualidade e competitividade. In: CONGRESSO LATINO-AMERICANO DE VITICULTURA E ENOLOGIA, 10., 2005. Bento Gonçalves. Anais... Bento Gonçalves: Embrapa Uva e vinho, 2005. p.195.

EMBRAPA UVA E VINHO. Brasil vitivinicola: regiões produtoras. Uvas americanas e híbridas para processamento em clima temperado. Disponível em: < www.cnpuv.embrapa.br/ publica/sprod/.htm>. Acesso em: 24 maio 2006.

FERREIRA, D. F. Análises estatísticas por meio Sisvar para Windows versão 4.0. In: REUNIÃO ANUAL DA SOCIEDADE INTERNACIONAL DE BIOMETRIA, 45., 2000. São Carlos. Anais... São Carlos: UFSCar, 2000. p.255-258.

INSTITUTO ADOLFO LUTZ. Normas analíticas do Instituto Adolfo Lutz: métodos químicos e físicos para análise dos alimentos. 3.ed. São Paulo, 1985. v.1.
INSTITUTO DE ENDOCRINOLOGIA E NUTRIÇÃO. Vinho ou suco de uva? Disponível em: <http://www.drien.com.br/ ien2003 alimentacao vinho ou suco de uva.htm>. Acesso em: 11 jun. 2005.

MELLO, L. M. R. Panorama. In: ANUÁRIO BRASILEIRO DA UVAE DO VINHO. Santa Cruz do Sul: Gazeta, 2006. p.17-18

RIZZON, L.A.; MANFROI, V.; MENEGUZZO, J. Elaboração de suco na propriedade vitícola. Bento Gonçalves: Embrapa Uva e Vinho, 1998.

RIZZON, L.A.; MENEGUZZO, J.; MANFROI, L. Processamento de uva, vinho tinto, graspa e vinagre. Brasília: Embrapa Informação Tecnológica, 2004.

RIZZON, L.A.; LINK, M. Composição do suco de uva caseiro de diferentes cultivares. Ciência Rural, Santa Maria, v.26, n. 2, p.689-692, 2006. 